\title{
Coronavirus Disease 2019 and Stroke
}

\author{
Jong S. Kim \\ Department of Neurology, Asan Medical Center, University of Ulsan College of Medicine, Seoul, Korea
}

World Health Organization declared coronavirus disease 2019 (COVID-19) a pandemic on 11 March 2020. As of 18 May 2020, more than 4.7 million cases have been diagnosed globally resulting in a tremendous impact on health and economy worldwide. In this COVID-19 pandemic era, stroke physicians and allied healthcare providers need to consider the following points.

First, it seems that stroke is attributed to COVID-19. However, the exact prevalence and pathogenic mechanisms of stroke in COVID-19 patients remain controversial. A report showed that about 6\% of COVID-19 patients have strokes. ${ }^{1}$ However, stroke patients account for only about 1\% of COVID-19 patients in Daegu, where the biggest COVID-19 outbreak of South Korea occurred (personal communication with Dr. Jun Lee). Because COVID-19 tests have been extensively performed in Korea, there may have been more mild or asymptomatic cases in Korea, which may explain the relatively low incidence of stroke in Korean COVID-19 patients.

Presumed stroke mechanisms include hypercoagulability and cardioembolism resulting from viral myocarditis or cardiac failure. Various mechanisms for coagulopathy in COVID-19 were discussed in this issue of Journal of Stroke, ${ }_{1}^{2}$ An additional mechanism would be through the renin-angiotensin system (RAS). Severe acute respiratory syndrome coronavirus 2 (SARS-CoV-2) viruses deplete angiotensin-converting enzyme 2 (ACE2) through receptor endocytosis upon viral entry, leaving ACE1 with unopposed generation of angiotensin II. The resulting activation of the RAS pathway may lead to increased sympathetic nervous system activation, excessive oxidative stress, and inflammatory/immunological responses. ${ }^{3}$

Another practical and critical issue is the potential for suboptimal stroke care due to fear of COVID-19 infection, shortage of medical resources, and staffing shortfalls. In this issue of Journal of Stroke, Korean stroke experts provided a consensus opinion on strategies to manage acute stroke patients in the COVID-19 pandemic era. ${ }^{4}$ Another study from Taiwan described strategies in stroke management established in Cheng Kung hospitals. ${ }^{5}$ They both suggested reasonable approaches for providing optimal stroke care while protecting the stroke team from COVID-19 infection. One commonality in almost all countries is the decreased number of stroke patients admitted these days. This is likely due to the fact that patients, especially those with mild symptoms, have refrained from seeking hospital treatment for fear of COVID-19 infection. Another possible explanation could be an actual decrease in stroke incidence as a result of reduced air pollution, a global factor related to the development of stroke. ${ }^{6}$

A report from Egypt in this issue, ${ }^{7}$ which compared the status of stroke patients before and after the COVID-19 pandemic, also showed fewer admitted cases. Thus, strokes in admitted patients were generally more severe than before. However, their report was not pessimistic. They found that the onset-to-door time was shortened and the proportion of patients receiving thrombolysis or thrombectomy actually increased. Although these findings may simply reflect that only severe cases visited the emergency department, the overall clinical outcome of admitted stroke patients was not different from that in the preCOVID-19 era.

Although COVID-19 infection is disastrous, even for stroke physicians, this may provide us with a rare opportunity to gain insight on the pathogenesis of stroke associated with infection. We also need to maintain optimism and try our best to establish strategies for providing effective stroke therapies to admitted stroke patients. However, given that patients with mild symptoms should also receive appropriate therapy, the decreased number of admitted patients is concerning. The overall impact of COVID-19 on outcomes of stroke patients (hospitalized and non-hospitalized) remains to be seen. It also remains to be observed cautiously what would be the eventual impact of the economic deterioration on stroke care in the COVID-19 era. 


\section{References}

1. Mao L, Jin H, Wang M, Hu Y, Chen $S$, He $Q$, et al. Neurologic manifestations of hospitalized patients with coronavirus disease 2019 in Wuhan, China. JAMA Neurol 2020 Apr 10 [Epub]. https://doi.org/10.1001/jamaneurol.2020.1127.

2. Montalvan V, De Toledo J, Nugent K. Mechanisms of stroke in coronavirus disease 2019. J Stroke 2020;22:282-283.

3. Hess DC, Eldahshan W, Rutkowski E. COVID-19-related stroke. Trans/ Stroke Res 2020 May 7 [Epub]. https://doi. org/10.1007/s12975-020-00818-9.

4. Kim BJ, Kim ES, Shin MJ, Kim HB, Lee HY, Hong KS, et al. Management of acute stroke patients amid the coronavirus disease 2019 pandemic: scientific statement of the Korean Stroke Society. J Stroke 2020;22:203-205.

5. Lin PY, Chang YM, Huang CY, Lin CH, Chuang MT, Chen PL, et al. Management of hyperacute stroke during the coronavirus disease of 2019 pandemic: the modified code stroke in a medical center in Taiwan. J Stroke 2020;22:278-281.

6. Lee KK, Miller MR, Shah ASV. Air pollution and stroke. J Stroke 2018;20:2-11.

7. Roushdy TM, El Nahas NM, Aref HM, Georgy SS, Zaki AS, Bedros RY, et al. Stroke in the time of coronavirus disease 2019: experience of two university stroke centers in Egypt. J Stroke 2020;22:275-277.

Correspondence: Jong S. Kim

Department of Neurology, Asan Medical Center, University of Ulsan College of Medicine, 88 Olympic-ro 43-gil, Songpa-gu, Seoul 05505, Korea

Tel: +82-2-3010-3440

Fax: +82-2-474-4691

E-mail: jongskim@amc.seoul.kr

The author has no financial conflicts of interest. 